\title{
COMMENT
}

\section{Blue or green for yellow? Which light is more beneficial for jaundiced newborns?}

\author{
Claudio Tiribelli (iD) $^{1}$ \\ Pediatric Research (2019) 85:747; https://doi.org/10.1038/s41390-019-0350-7
}

Sister Ward, a bright nurse at the Premature Unit at Rochford General Hospital in Essex, England, was used to expose the newborns outdoor despite the resistance of the doctors at this practice. One sunny summer day in 1956 she noticed that the portion of the skin exposed to the sun was much paler than the yellow color of the skin covered by the sheets. Subsequently, researchers at Rochford Hospital convincingly showed that the level of bilirubin was much lower in tubes exposed to light leading to the idea of phototherapy for neonatal jaundice which they then developed with the first phototherapy unit with an artificial light source.

Despite the decades of use of phototherapy for the management of severe neonatal jaundice, the optimum wavelength range for bilirubin photodegradation is still a matter of controversy. The standard phototherapy approach is based on the 460-nm concept, i.e., the light wavelength corresponding to the absorption maximum of bilirubin. Although used worldwide, a few studies suggested that the use of blue-green light with higher wavelengths above $490 \mathrm{~nm}$ might be of therapeutic value., ${ }^{2,3}$ In this issue of Pediatric Research, Vreman et al. report a detailed in vitro study on the efficacy of the bilirubin photodegradation at various wavelengths. ${ }^{4}$ Contrary to the general thinking, the $510-\mathrm{nm}$ wavelength was found to be more efficient compared to the standard and clinically used wavelength of $460 \mathrm{~nm}$. The authors demonstrated that the lumirubin production is enhanced at higher wavelengths because of the complex photophysical properties of bilirubin, the $4 E, 15 Z$-isomer of which is responsible for lumirubin formation.

It should be noted that we still know too little about the lumirubin kinetics and dynamics in a body. The main reason is the lack of experimental and analytical techniques, as well as chemical standards to be used for such investigations. Thus, we do not know (1) how much lumirubin is excreted through the urinary and/or biliary system; (2) whether lumirubin can cross the blood-brain barrier; (3) how stable lumirubin is in the circulation and tissues; and (4) whether its possible degradation products exert any biological activities.

It also needs to be emphasized that human body is a complex machinery and, as discussed by Vreman et al., the efficacy of the light therapy is influenced by numerous factors, including skin optical properties, red blood cells present in the skin capillaries, and interactions of bilirubin photodegradation products with molecules such as albumin or fatty acids. ${ }^{5-7}$ Only clinical studies on human neonates with proper analytical methods focused on the determination of bilirubin photodegradation products in various biological fluids will uncover and solve the problem of assessment of the most appropriate phototherapy wavelength.

After 53 years from the extraordinary observation of sister Ward, we clearly have still a long way to go. Whether we should shift the wavelength of our phototherapy units from 460 to $510 \mathrm{~nm}$ needs to be proved in prospective clinical trials, but the in vitro observation of this manuscript provides the solid scientific background for such studies. This is important not only for an effective and rapid decline in serum bilirubin but also to assess the effect of the new light in the production of lumirubin and other photoderivatives that may have effects on the newborns. ${ }^{8}$

\section{ACKNOWLEDGEMENTS}

This work was partially supported by in-house grant from Fondazione Italiana Fegato.

\section{ADDITIONAL INFORMATION}

Competing interests: The authors declare no competing interests.

Publisher's note: Springer Nature remains neutral with regard to jurisdictional claims in published maps and institutional affiliations.

\section{REFERENCES}

1. Cremer, R. J., Perryman, P. W. \& Richards, D. H. Influence of light on the hyperbilirubinemia of infants. Lancet 1, 1094-1097 (1958).

2. Ebbesen, F., Agati, G. \& Pratesi, R. Phototherapy with turquoise versus blue light Arch. Dis. Child Fetal Neonatal Ed. 88, F430-F431 (2003).

3. Ebbesen, F., Madsen, P., Stovring, S., Hundborg, H. \& Agati, G. Therapeutic effect of turquoise versus blue light with equal irradiance in preterm infants with jaundice. Acta Paediatr. 96, 837-841 (2007).

4. Vreman, H. J. et al. The effect of light wavelength on in vitro bilirubin photodegradation and photoisomer production. Pediatr. Res. https://doi.org/10.1038/ s41390-019-0310-2 (2019).

5. Malhotra, V., Greenberg, J. W., Dunn, L. L. \& Ennever, J. F. Fatty acid enhancement of the quantum yield for the formation of lumirubin from bilirubin bound to human albumin. Pediatr. Res. 21, 530-533 (1987).

6. Goncharova, I., Jasprova, J., Vitek, L. \& Urbanova, M. Photo-isomerization and oxidation of bilirubin in mammals is dependent on albumin binding. Anal. Biochem. 490, 34-45 (2015).

7. Lamola, A. A., Bhutani, V. K., Wong, R. J., Stevenson, D. K. \& McDonagh, A. F. The effect of hematocrit on the efficacy of phototherapy for neonatal jaundice. Pediatr. Res. 74, 54-60 (2013).

8. Jašprová, J. et al. Neuro-inflammatory effects of photodegradative products of bilirubin. Sci. Rep. 8, 7444 (2018).

${ }^{1}$ Fondazione Italiana Fegato BIdg Q, AREA Science Park- Campus Basovizza, 34149 Trieste, Italy

Correspondence: Claudio Tiribelli (ctliver@fegato.it)

Received: 5 February 2019 Accepted: 13 February 2019

Published online: 21 February 2019 